\title{
A Cross-Sectional Survey on Non-Communicable Diseases and Risk Factors in the Senegalese Army
}

\author{
Abdoul Aziz Ndiaye ${ }^{1,2 *}$, Alioune Badara Tall1,2, Boubacar Gueye1,2, Ibrahima Soce Fall1,3, \\ Sidy Mouhamed Seck , Amady Barro Mbodj², Ndeye Fatou Ngom-Gueye1, Awa Gaye1, Anta Tal-Dia ${ }^{5}$ \\ ${ }^{1}$ Community Health Department, University Alioune Diop of Bambey, Bambey City, Senegal \\ ${ }^{2}$ Army Health Service, Camp Dial Diop, Dakar, Senegal \\ ${ }^{3}$ WHO, Bamako, Mali \\ ${ }^{4}$ Faculty of Health Sciences, Gaston Berger University, Saint-Louis, Senegal \\ ${ }^{5}$ Public Health Department, Cheikh Anta Diop University, Dakar, Senegal \\ Email: *abdoulaziz.ndiaye@uadb.edu.sn, ^ndiaziz2000@yahoo.fr, tallalioune@yahoo.fr, boubsan2000@yahoo.fr, socef@who.int, \\ sidymseck@gmail.com,mbodjamadybarro@yahoo.fr, ndeyetouti98@gmail.com,awa.gaye@uadb.edu.sn, adia@ised.sn
}

How to cite this paper: Ndiaye, A.A., Tall, A.B., Gueye, B., Fall, I.S., Seck, S.M., Mbodj, A.B., Ngom-Gueye, N.F., Gaye, A. and TalDia, A. (2016) A Cross-Sectional Survey on Non-Communicable Diseases and Risk Factors in the Senegalese Army. Health, 8, 1529-1541.

http://dx.doi.org/10.4236/health.2016.814151

Received: October 19, 2016

Accepted: November 14, 2016

Published: November 17, 2016

Copyright $\odot 2016$ by authors and Scientific Research Publishing Inc. This work is licensed under the Creative Commons Attribution International License (CC BY 4.0).

http://creativecommons.org/licenses/by/4.0/

cc) (i) Open Access

\section{Abstract}

Background: The non-communicable diseases (NCDs) have become a public health priority. The objectives of this study were to measure the prevalence and to assess the risk factors of NCDs among the Senegalese military population to initiate an intervention program. Methods: A cross-sectional survey was conducted in 2014. Twolevel stratification was used to sample participants. Data were collected following the protocol recommended by the World Health Organization. Data were managed using Epi-Info 6 software and analyzed using R software. Results: A total of 1224 participants were recruited, of whom $96.9 \%$ were men. Their ages ranged from 25 to 60 years with a mean of $39.7 \pm 9.2$ years. Of participants, $17.2 \%$ were active smokers. Average duration of active smoking was $19.9 \pm 9$ years. The prevalence of current alcohol consumption was $11.5 \%$, with an average of $4 \pm 2.7$ glasses a day. $97.17 \%$ of participants consumed fewer than 5 servings of fruits and vegetables a day. $18.63 \%$ had insufficient physical activity. The overall prevalence of high blood pressure was $26.9 \%$. The proportion of those who were overweight was $27.2 \% ; 3.3 \%$ were obese. $3.0 \%$ of participants had diabetes and $44.1 \%$ had hypercholesterolemia. After adjusting for waist circumference, the risk of high cholesterol was 2.42 in the $35-44$ age group and 2.86 in the 45 - 60 age group in comparison with the 25 - 34 age group. $32 \%$ were classified as having stage 2 chronic kidney. Conclusions: The findings of this study indicate the importance of risk factors for NCDs in the Senegalese military population. Intervention based on prevention and health promotion is needed.

\section{Keywords}

Risk Factors, NCDs, Military 


\section{Background}

NCDs are a global public health priority [1] [2]. In developing countries, there exists a double epidemiological burden of both communicable and non-communicable diseases [3] [4]. Indeed, NCDs are responsible for 35 million of the 53 million deaths worldwide; three-quarters of these deaths occur in low-income or middle-income countries [2] [5] [6]. The epidemiological transition observed in industrialized countries seems to affect developing countries [7] [8]. Population growth, rapid urbanization and change in lifestyle are fueling the emergence of NCDs [7] [8] [9]. Furthermore, people who are in precarious socio-economic situations are the most vulnerable [2].

Despite the increase of NCDs, health prevention programs are still primarily focused on communicable diseases in developing countries [10]. For example, Millennium Development Goal 6 is dedicated to the fight against HIV/AIDS, malaria and tuberculosis, and to the mobilization of significant funding to fight these diseases [10]. However, the World Health Organization forecasts a global epidemic of non-communicable diseases in 2030 [11] and recommends that low and middle-income countries develop NCD maps, including their determinants, to implement appropriate control programs [12] [13] [14]. In addition, the United Nations passed a resolution to reduce premature mortality by $25 \%$ by 2025 , an initiative that involves private entities and civil society [3] [10] [13] [15] [16].

In Senegal, several well-organized programs are dedicated to the fight against communicable diseases. However, there is no dedicated program for NCDs and case management is currently the main protocol. In coming years, the availability of epidemiological data and the development of a multi-sector approach will present challenges to NCD control.

To address these concerns, this study was carried out to assess NCD risk factors in the army to establish a sector-specific program for Senegalese military personnel.

\section{Methods}

We conducted a descriptive and analytical cross-sectional study on the key risk factors (behavioral, physical and biological) of non-communicable diseases.

The study population consisted of Senegalese military personnel. Sample size was calculated using a $25 \%$ estimated theoretical prevalence of high blood pressure, with $5 \%$ accuracy and $1.5 \%$ design effect [17]. For each stratum, 432 subjects were to be investigated, thus. The total estimated sample size was 1296 individuals. Two-level stratification was used to determine the number of individuals to be surveyed in each training unit and also in each age group. Statistical units were selected in the field using a simple random sampling approach.

Only military personnel aged 25 - 60 years who were in Senegal during the study period were included. Those who did not want to participate in the survey or were unable to answer questions were excluded from the study. Also, the military personnel under 25 years old were excluded. The enrolled population was divided into three age-based strata: 25 - 34; 35 - 44 and 45 - 60 years old. 
A previously validated version of the STEPS questionnaire was used after adapting for context [18] [19]. The questionnaire included three sections including socio-demographic and behavioral information, anthropometric and cardiovascular measures, and biochemical parameters. Participation in the study was voluntary and free of charge. Data were entered using Epi Info 6 software and analyzed using R software.

Consumption of fruits and vegetables was considered insufficient below 5 daily servings. A serving was defined as 80 grams of fruits and/or vegetables, and estimation was performed using a validated chart. The WHO recommends a daily consumption of 400 grams or 5 servings of fruits and vegetables [18] [19]. The physical activity assessment took into account all activities related to leisure, work and daily trips. Physical activity was considered moderate when it was sustained for 30 minutes and resulted in a moderate heart rate increase. Physical activity was defined as high when it was a session of recreation or sports that was sustained for at least 30 minutes and resulted in a significant heart rate increase [18] [19] [20]. Participants who performed fewer than five intense physical activities weekly were considered inactive [18] [19] [20].

Current smokers were those who used cigarettes daily [20], while alcohol consumption was defined as the use of alcohol in the last 30 days [19].

Overweight was defined as a body mass index (BMI) between 25 and $30 \mathrm{~kg} / \mathrm{m}^{2}$, and obesity as a BMI greater than or equal to $30 \mathrm{~kg} / \mathrm{m}^{2}$ [18] [19] [20] [21].

Participants were classified as diabetic based on a fasting blood glucose level $\geq 126$ $\mathrm{mg} / \mathrm{l}$ or when the participant was under anti-diabetes treatment [20]. High blood pressure was indicated by systolic blood pressure $\geq 140 \mathrm{~mm} \mathrm{Hg}$ and/or diastolic blood pressure $\geq 90 \mathrm{~mm} \mathrm{Hg}$ or by regular use of antihypertensive therapy [18] [19] [20] [21]. Hypercholesterolemia was defined by a total cholesterol rate $\geq 250 \mathrm{mg} / \mathrm{dl}$ and/or a LDH cholesterol value below $40 \mathrm{mg} / \mathrm{dl}$ and/or triglyceride levels $\geq 150 \mathrm{mg} / \mathrm{dl}$ [20] [22] [23].

The glomerular filtration rate (GFR) was assessed using the Modification of Diet in Renal Disease (MDRD) formula [24] [25] [26] [27]. Chronic kidney disease was defined by a GFR below $60 \mathrm{ml} / \mathrm{min} / 1.73 \mathrm{~m}^{2}$. Two CKD stages were identified: Stage 1 represented a GFR greater than $90 \mathrm{ml} / \mathrm{min} / 1.73 \mathrm{~m}^{2}$; Stage 2 was represented a GFR between 60 and $90 \mathrm{ml} / \mathrm{min} / 1.73 \mathrm{~m}^{2}$ [24] [25] [26] [27].

Chi-square test was performed to compare proportions, with a significance level set at $5 \%$. Odds ratios with $95 \%$ confidence interval were used to estimate the risk in simple and multiple logistic regression models. In this context, effects on the incidence of high blood pressure of age, BMI $\geq 25 \mathrm{~kg} / \mathrm{m}^{2}$, hypercholesterolemia, smoking and physical activity were verified. Similarly, effects on the occurrence of hyperlipidemia of age, physical activity, consumption of fruits and vegetables, alcohol consumption in the last thirty days and waist circumference were assessed. A likelihood test was used for this purpose.

Ethics statement: Each participant signed a consent letter before entering the study. Additionally, each participant was informed about his medical profile at the conclusion of data collection; appropriate advice was given and case management delivered according to identified health problems. 
In compliance with national regulations, the Director of Senegalese military medical support approved the study among the military and its publication was authorized by Senegalese ethics national committee.

\section{Results}

The study was conducted over a period of ten months. A total of 1224 individuals participated. No cases of refusal were reported.

The mean and median ages were the same: both equaled 40 years (normal distribution of the sample). The average age at beginning of smoking was $20.8 \pm 4$ years and the average number of years of active smoking was $19.9 \pm 9$ years, with $9.5 \pm 4$ cigarettes smoked/day. The average alcohol intake was $2.7 \pm 4$ glasses per day. The mean BMI was $23.7 \pm 3.1 \mathrm{~kg} / \mathrm{m}^{2}$ and the average waist circumference size was $85.6 \pm 8 \mathrm{~cm}$.

The average cholesterol level was $1.93 \pm 0.42 \mathrm{~g} / \mathrm{l}$; the average HDL-cholesterol level was $0.52 \pm 0.16 \mathrm{~g} / \mathrm{l}$, while the average triglycerides level was $0.82 \pm 0.44 \mathrm{~g} / \mathrm{l}$. The average MDRD was $109 \pm 31.2 \mathrm{ml} / \mathrm{min} / 1.73 \mathrm{~m}^{2}$.

Table 1 shows the behavioral determinants of NCDs among Senegalese soldiers. The prevalence of current active smokers was $17.2 \%(95 \% \mathrm{CI}=15-19)$ and did not vary significantly between the different age groups $(p=0.73)$. At the same time, the percentage of history of active smoking was higher among the over 45 age group.

The prevalence of alcohol consumption ( $11.5 \%$ overall, [95\% CI $=9.8-13.4]$ ), varied between strata $(p=0.02)$. It was significantly higher among $35-60$ year olds $(13 \%)$ and relatively low among 25 - 34 year olds (7.5\%).

The proportion of participants who consumed insufficient amounts of fruits and vegetables was considerable; 9 out of 10 respondents consumed five or fewer servings of fruits and vegetables per day, 4 out 10 consumed fewer than three servings per day.

Among participants, $46 \%$ (95\% CI $=43.3 \%$ - 49\%) engaged in intense or moderate physical activity. This percentage decreased significantly with age $(p<0.001)$. Low physical activity was observed in one out of five participants and increased with age ( $p$ $<0.001$ ). The prevalence of low physical activity was higher in the over 44 age group and observed less often among those under 35 years old.

Table 2 shows the distribution of respondents according to physical determinants. Overall prevalence of overweight participants was $27.2 \%$. Obesity was rare; only $3.3 \%$ $(95 \% \mathrm{CI}=2.4-4.5)$ of participants had a BMI above $30 \mathrm{~kg} / \mathrm{m}^{2}$. Overweight or obesity was more frequently observed among those aged 35 years and over. Prevalence of overweight was 3 and 4 times higher in the 35 - 44 and 45 - 60 age groups, respectively, compared to those under 35 years old.

The proportion of military staff with a waist circumference greater than $94 \mathrm{~cm}$ was $15 \%$. It was more common in those over 44 years old.

The proportion of participants with high blood pressure that was detected for the first time during the study was $25 \%$; $2 \%$ were already on antihypertensive therapy. Thus, the overall prevalence of hypertension was $27 \%(95 \%$ CI $=24.4-29.5)$. It was more common in the 45 - 60 age group $(p<0.001)$. 
Table 1. Lifestyle risk factors for non-communicable diseases among Senegalese military personnel.

\begin{tabular}{|c|c|c|c|c|c|}
\hline & All & 25 - 34 years & 35 - 44 years & $45-60$ years & $p$ value \\
\hline \multicolumn{6}{|l|}{ Tobacco consumption } \\
\hline Current smoking & 210 & 59 & 76 & 75 & 0.73 \\
\hline$\%$ & 17.2 & 15.7 & 18.1 & 17.6 & \\
\hline $\mathrm{IC}_{95 \%}$ & {$[15-19]$} & {$[12.2-19.8]$} & {$[14.5-22.0]$} & {$[14.1-21.6]$} & \\
\hline History of smoking & 303 & 43 & 110 & 150 & $<0.001$ \\
\hline$\%$ & 29.8 & 13.5 & 31.9 & 42.5 & \\
\hline $\mathrm{IC}_{95 \%}$ & {$[27-32.7]$} & {$[10.0-17.8]$} & {$[27.0-37.1]$} & {$[37.8-47.8]$} & \\
\hline \multicolumn{6}{|l|}{ Alcohol consumption } \\
\hline In the last 12 months & 190 & 43 & 72 & 75 & 0.031 \\
\hline$\%$ & 15.5 & 11.4 & 17.1 & 17.6 & \\
\hline $\mathrm{IC}_{95 \%}$ & {$[13.5-17.7]$} & {$[8.4-15.1]$} & {$[13.6-21.0]$} & {$[14.1-21.5]$} & \\
\hline In the last 30 days & 141 & 27 & 56 & 58 & 0.006 \\
\hline$\%$ & 11.5 & 7.2 & 13.3 & 13.6 & \\
\hline $\mathrm{IC}_{95 \%}$ & {$[9.8-13.4]$} & {$[4.8-10.3]$} & {$[10.2-16.9]$} & {$[10.5-17.2]$} & \\
\hline \multicolumn{6}{|l|}{$\begin{array}{l}\text { Daily consumption of } \\
\text { fruits and vegetables }\end{array}$} \\
\hline \multicolumn{6}{|l|}{ Five or fewer servings } \\
\hline Number & 1167 & 368 & 394 & 405 & 0.026 \\
\hline$\%$ & $97.17 \%$ & $98.90 \%$ & $97.0 \%$ & $95.74 \%$ & \\
\hline $\mathrm{IC}_{95 \%}$ & {$[96.1-98.0]$} & {$[97.3-99.7]$} & {$[94.9-98.5]$} & {$[93.3-97.5]$} & \\
\hline \multicolumn{6}{|l|}{ Fewer than 3 servings } \\
\hline Number & 475 & 136 & 161 & 178 & 0.28 \\
\hline$\%$ & $39.55 \%$ & $36.56 \%$ & $39.66 \%$ & $42.08 \%$ & \\
\hline $\mathrm{IC}_{95 \%}$ & {$[36.8-42.4]$} & {$[31.6-41.7]$} & {$[34.8-44.6]$} & {$[37.3-46.9]$} & \\
\hline \multicolumn{6}{|l|}{ Physical activity } \\
\hline Intense or moderate & 565 & 211 & 196 & 158 & $<0.001$ \\
\hline$\%$ & 46.16 & 56.12 & 46.56 & 37.00 & \\
\hline $\mathrm{IC}_{95 \%}$ & {$[43.3-49.0]$} & {$[51.0-61.2]$} & {$[41.7-51.4]$} & {$[32.4-41.8]$} & \\
\hline Low & 228 & 66 & 63 & 99 & 0.007 \\
\hline$\%$ & 18.63 & 17.55 & 14.96 & 23.19 & \\
\hline $\mathrm{IC}_{95 \%}$ & {$[16.2-20.9]$} & {$[13.8-21.8]$} & {$[11.7-18.7]$} & {$[19.7-27.5]$} & \\
\hline
\end{tabular}

Table 2. Clinical characteristics of Senegalese military personnel with NCDs.

\begin{tabular}{cccccc}
\hline & All & $25-34$ years & $35-44$ years & $45-60$ years & $p$ value \\
\hline BMI $\left(\mathrm{kg} / \mathrm{m}^{2}\right)$ & & & & & \\
Normal & 850 & 339 & 274 & 237 & $<0.001$ \\
$\%$ & 69.4 & .2 & 65.1 & 55.5 & \\
IC $_{95 \%}$ & {$[66.8-72]$} & {$[86.7-93]$} & {$[60.3-69.6]$} & {$[50.6-60.3]$} & \\
Overweight & 333 & 34 & 129 & 170 & $<0.001$ \\
$\%$ & 27.2 & 9.0 & 30.6 & 39.8 & \\
\hline
\end{tabular}




\section{Continued}

\begin{tabular}{|c|c|c|c|c|c|}
\hline \\
\hline $\mathrm{IC}_{95 \%}$ & {$[24.7-29.8]$} & {$[6.3-12.4]$} & {$[26.3-35.3]$} & {$[35.1-44.6]$} & \\
\hline Obesity & 41 & 3 & 18 & 20 & NV \\
\hline$\%$ & 3.3 & 0.8 & 4.3 & 4.7 & \\
\hline $\mathrm{IC}_{95 \%}$ & {$[2.4-4.5]$} & {$[0.16-2.31]$} & {$[2.55-6.67]$} & {$[2.9-7.1]$} & \\
\hline Overweight or obesity & 374 & 37 & 147 & 190 & $<0.001$ \\
\hline$\%$ & 30.6 & 9.8 & 34.9 & 44.5 & \\
\hline $\mathrm{IC}_{95 \%}$ & {$[28.0-33.2]$} & {$[7-13.3]$} & {$[30.3-39.7]$} & {$[39.7-49.4]$} & \\
\hline Waist circumference $>=94 \mathrm{~cm}$ & 185 & 25 & 63 & 97 & $<0.001$ \\
\hline$\%$ & 15.13 & 6.65 & 14.96 & 22.77 & \\
\hline $\mathrm{IC}_{95 \%}$ & {$[13.2-17.3]$} & {$[4.3-9.7]$} & {$[11.7-18.7]$} & {$[18.9-27.1]$} & \\
\hline \multicolumn{6}{|l|}{ Blood pressure } \\
\hline Systolic & 245 & 63 & 76 & 106 & 0.007 \\
\hline$\%$ & 20.0 & 16.8 & 18.1 & 24.8 & \\
\hline $\mathrm{IC}_{95 \%}$ & {$[17.8-22.4]$} & {$[13.1-20.9]$} & {$[14.5-22.1]$} & {$[20.8-29.3]$} & \\
\hline Diastolic & 239 & 59 & 78 & 102 & 0.011 \\
\hline$\%$ & 19.5 & 15.7 & 18.5 & 23.9 & \\
\hline $\mathrm{IC}_{95 \%}$ & {$[17.3-21.9]$} & {$[12.2-19.8]$} & {$[14.9-22.6]$} & {$[20-28.3]$} & \\
\hline $\mathrm{HSBP}^{\star}$ or $\mathrm{HDBP}^{\star}$ & 306 & 78 & 102 & 126 & 0.014 \\
\hline$\%$ & 25.0 & 20.7 & 24.2 & 29.5 & \\
\hline $\mathrm{IC}_{95 \%}$ & {$[22.6-27.5]$} & {$[16.8-25.2]$} & {$[20.2-28.6]$} & {$[25.3-34.2]$} & \\
\hline Hypertension medication & 23 & 0 & 5 & 18 & $\mathrm{NV}$ \\
\hline$\%$ & 1.9 & 0.0 & 1.2 & 4.2 & \\
\hline $\mathrm{IC}_{95 \%}$ & {$[1.2-2.8]$} & & {$[0.39-2.75]$} & {$[2.51-6.58]$} & \\
\hline Overall high blood pressure & 329 & 78 & 107 & 144 & $<0.001$ \\
\hline$\%$ & 26.9 & 20.7 & 25.4 & 33.7 & \\
\hline $\mathrm{IC}_{95 \%}$ & {$[24.4-29.5]$} & {$[16.8-25.2]$} & [21.3 - 29.9] & [29.4 - 38.6] & \\
\hline
\end{tabular}

HSBP*: High Systolic Blood Pressure; HDBP*: High Diastolic Blood Pressure.

Table 3 shows the biochemical parameters relevant to some non-communicable diseases. The prevalence of diabetes was low at $3 \%(95 \% \mathrm{CI}=2.1-4.1)$.

The prevalence of hypercholesterolemia was $44.07 \%(95 \%$ CI $=41.6-47)$. Hypercholesterolemia tended to increase with age $(p<0.001)$, increasing from $27.4 \%$ in the 25 - 34 age group to $49 \%$ in the 35 - 44 age group and $54.3 \%$ in the $45-60$ age group. High total cholesterol level was often responsible for hyperlipidemia; 37.5\% (95\% CI = 34.7 - 40.3) of participants with hyperlipidemia had cholesterol levels above normal.

The prevalence of stage 1 chronic kidney disease was $68 \%$ in this study population (GFR $>90 \mathrm{ml} / \mathrm{min} / 1.73 \mathrm{~m}^{2}$ ); $32 \%$ were classified as having stage 2 chronic CKD (GFR value between 60 and $90 \mathrm{ml} / \mathrm{min} / 1.73 \mathrm{~m}^{2}$ ). The prevalence of stage $2 \mathrm{CKD}$ was twice as high among those over 34 years old compared to those under 34 years old.

The results of the logistic regression are presented in Table 4. A simple model shows that age category, BMI $\geq 25 \mathrm{~kg} / \mathrm{m}^{2}$ and high cholesterol seemed to be risk factors for high blood pressure. Multiple regression controlling for the effect of overweight and 
Table 3. Biochemical characteristics of NCDs among Senegalese military personnel.

\begin{tabular}{|c|c|c|c|c|c|}
\hline & All & 25 - 34 years & $35-44$ years & 45 - 60 years & $p$ value \\
\hline \multirow[t]{3}{*}{ Diabetes } & 37 & 2 & 7 & 28 & NA \\
\hline & 3.03 & 0.53 & 1.66 & 6.57 & \\
\hline & {$[2.1-4.1]$} & {$[0.06-1.91]$} & {$[0.67-3.40]$} & {$[4.4-9.3]$} & \\
\hline Hypercholesterolemia-total & 446 & 86 & 167 & 193 & $<0.001$ \\
\hline$\%$ & 37.51 & 23.12 & 41.13 & 46.96 & \\
\hline $\mathrm{IC}_{95 \%}$ & {$[34.7-40.3]$} & {$[18.9-27.7]$} & {$[36.3-46.1]$} & {$[42-51.9]$} & \\
\hline Hypocholesterolemia-HDL & 128 & 22 & 54 & 52 & 0.001 \\
\hline$\%$ & 10.77 & 5.91 & 13.30 & 12.65 & \\
\hline $\mathrm{IC}_{95 \%}$ & {$[9.1-12.7]$} & {$[3.7-8.8]$} & {$[10.2-17]$} & {$[9.6-16.3]$} & \\
\hline Hypertriglyceridemia & 50 & 5 & 23 & 22 & 0.004 \\
\hline$\%$ & 4.21 & 1.34 & 5.67 & 5.35 & \\
\hline $\mathrm{IC}_{95 \%}$ & {$[3.1-5.5]$} & {$[0.4-3.1]$} & {$[3.6-8.4]$} & {$[3.4-8.0]$} & \\
\hline Hyperlipidemia & 524 & 102 & 199 & 223 & $<0.001$ \\
\hline$\%$ & 44.07 & 27.42 & 49.01 & 54.26 & \\
\hline $\mathrm{IC}_{95 \%}$ & {$[41.2-47.0]$} & {$[23.0-32.3]$} & {$[44.1-54.0]$} & {$[49.3-59.1]$} & \\
\hline \multicolumn{6}{|l|}{ Chronic kidney disease } \\
\hline \multicolumn{6}{|l|}{ Glomerular filtration rate } \\
\hline $60-90 \mathrm{ml} / \mathrm{min} / 1.73 \mathrm{~m}^{2}$ & 389 & 63 & 157 & 169 & $<0.001$ \\
\hline$\%$ & 31.86 & 16.76 & 37.38 & 39.76 & \\
\hline $\mathrm{IC}_{95 \%}$ & {$[29.3-34.6]$} & {$[13.1-21.0]$} & {$[32.7-42.2]$} & {$[35.1-44.6]$} & \\
\hline$\geq 90 \mathrm{ml} / \mathrm{min} / 1.73 \mathrm{~m}^{2}$ & 832 & 313 & 263 & 256 & 0.001 \\
\hline$\%$ & 68.14 & 83.24 & 62.62 & 60.24 & \\
\hline $\mathrm{IC}_{95 \%}$ & {$[65.4-70.7]$} & {$[79.1-86.9]$} & {$[58.0-67.3]$} & {$[55.4-64.9]$} & \\
\hline
\end{tabular}

Table 4. Crude and adjusted odd ratios for high blood pressure and hypercholesterolemia risk among Senegalese military personnel.

\begin{tabular}{ccccc}
\hline & Crude OR & $95 \% \mathrm{CI}$ & Adjusted OR & $95 \%$ CI \\
\hline HBP risk & & & & \\
Age group & & & & \\
$35-44$ years & 1.33 & {$[0.95-1.86]$} & 1.02 & {$[0.72-1.45]$} \\
$45-60$ years & 1.96 & {$[1.42-2.71$} & 1.41 & {$[0.99-1.99]$} \\
BMI $\geq 25$ kg/m ${ }^{2}$ & 1.87 & {$[1.43-2.44]$} & 1.58 & {$[1.18-2.10]$} \\
Hyperlipidemia & 2.14 & {$[1.65-2.77]$} & 1.93 & {$[1.48-2.52]$} \\
Hyperlipidemia risk & & & & \\
Age group & & & & \\
$35-44$ years & 2.54 & {$[1.88-3.43]$} & 2.42 & {$[1.79-3.28]$} \\
$45-60$ years & 3.14 & {$[2.33-4.24]$} & 2.86 & {$[1.1-3.87]$} \\
Waist circumference* $\geq 94 \mathrm{~cm}$ & 2.31 & {$[1.67-3.21]$} & 1.93 & {$[1.38-2.71]$} \\
\hline
\end{tabular}

${ }^{\star}$ Waist circumference $=$ waist - hip ratio. 
hyperlipidemia showed that the risk of hypertension is not significantly different between age groups. However, BMI $\geq 25 \mathrm{~kg} / \mathrm{m}^{2}$ and hypercholesterolemia multiplied the risk of high blood pressure by 1.5 and 2, respectively. The risk of hyperlipidemia was found to increase with age and with waist circumference above $90 \mathrm{~cm}$. When compared with the 25 - 34 age group, the risk of hyperlipidemia was $2.42(95 \% \mathrm{CI}=1.79-3.28)$ and $2.86(95 \% \mathrm{CI}=1.1-3.87)$ times higher among $35-44$ and 45 - 60 year olds, respectively. Abdominal obesity multiplied the risk of hypercholesterolemia by 1.93 (95\% CI $=1.38-2.71)$.

\section{Discussion}

Despite WHO recommendations for the implementation of STEPS surveys in developing countries [12], few studies on the determinants of NCDs have been conducted in Sub-Saharan Africa [4]. In Senegal, only piecemeal studies on specific groups have been published [17] [28] [29] [30].

As a group, the military is considered to be a lower risk group for NCDs. Military members are selected between the ages of $18-22$ on the basis of rigorous clinical and laboratory screening criteria. In addition, during their career, military members have regular follow-ups and have support in case of illness. Paradoxically, this study revealed the regularity of NCD risk factors among Senegalese military.

The presence of behavioral risk factors studied is one example. The prevalence of current tobacco smoking, $17.2 \%$, is higher than that observed in studies by Seck et al. (7.5\%) and Mbaye et al. (5.8\%) [17] [28]. This finding confirms the conclusions of some authors that asserted that the army is an environment of freedom compared to the social restrictions that exist in civilian populations [31].

In contrast, the frequency of alcohol consumption (11.5\%) was slightly higher in the study by Seck et al. (18\%) [17]. In the military, this consumption was irregular, especially during the holidays.

Consumption of fruits and vegetables in sufficient quantity was not a common practice in the military; only $4 \%$ consumed an average of more than five servings per day. Some authors have shown that in developing countries, people eat what is available and cheap [7] [32] [33]. The food industry tends to bring to market energy-dense products that are nutritionally poor but attractively priced [7]. The frequency of dyslipidemia observed in our study correlates with this view; the prevalence of hyperlipidemia was significant (44\%) in relation to total cholesterol (37\%), hypo-HDL cholesterol (10.8\%) and hypertriglyceridemia (4.2\%). This indicates that hyperlipidemia was primarily attributable to total cholesterol. The high content of saturated fatty acid in foods may explain the role of total cholesterol in the occurrence of dyslipidemia observed in our study.

Compared to our study, Mbaye et al. observed a greater prevalence of hyperlipidemia (64.6\%), the same total cholesterol (36.3\%), a greater prevalence of hypo-HDL cholesterol (41.9\%), and similarly low hypertriglyceridemia (1.2\%) [28]. However, unlike our study, HDL cholesterol was responsible for dyslipidemia in a previous survey con- 
ducted in Saint-Louis (northern Senegal) [28]. Physical activity is a very important aspect of the Army; military exams and courses assign a high coefficient to physical activity. Thus, in the average soldier's work schedule, two sessions of sports are scheduled every week. This rule is correlated with the median practice of intense physical activity observed in this study. Taking work activity into resulted in a median of 4 moderate or intense sessions a week. However, 38\% were below the standard of 5 moderate or intense sessions a week. The same frequency was mentioned by Seck et al. [17]. This lack of practice was linked to organizational and informational problems within the army.

Overweight or obesity affected 3 out of 10 study participants, suggesting small amounts of exercise for some military staff, particularly those over 34 years old. This is in line with the practice of making physical activity non-compulsory for managers and elders, who have fewer physical training constraints during internship. The combination of poor diet rich in saturated fatty acid and insufficient physical activity may be the cause of this situation. However, previous studies in the Senegalese general population found a prevalence that was twice as high, approximately $66 \%$ [17] [28].

High blood pressure is both a risk factor for NCDs (heart disease, CKD) and also an NCD itself. The estimated prevalence of $26.9 \%$ in the military is identical to what was found by Seck et al. (24.1\%) in Senegalese private sector workers [17]. Other authors have reported higher proportions, probably related to the study population [28] [29] [30]. This finding correlates with the results of the multivariate analysis which found that overweight, which is less common in the military, is a determinant of high blood pressure.

A study of the military in southern Tunisia reported a lower prevalence of hypertension (15.6\%) [34]. The difference, compared with the prevalence observed in our study, could be explained by the high consumption of salt in Senegal, which is reinforced by the heavy use of food stocks due to the aggressive advertising of certain food processors [32].

The prevalence of hyperglycemia, estimated at $3.03 \%$ in our study, was three times lower than that observed in another Senegalese study (10.4\%) [28]. In the latter study, the population was older, with a mean age of 58 years. In addition, physical inactivity and overweight were more frequent. A recent study in northern Senegal supports the work of Mbaye et al., reporting a diabetes prevalence of $12.7 \%$ [30]. In contrast, a study conducted on the Tunisian military reported a prevalence almost identical to that found in our study (5.6\%) [34].

In the rural Yoruba ethnic group (Nigeria), high blood pressure was found in $42.3 \%$ of men, diabetes in $1.9 \%$, obesity in $3.6 \%$ and abdominal obesity $14.7 \%$. The prevalence of hypertriglyceridemia and HDL-hypocholesterolemia were $1.9 \%$ and $43.1 \%$, respectively. These results demonstrate the variability of NCD epidemiology based on geographic, socio-cultural and professional context [20].

Worldwide, the incidence of CKD is growing, with faster rates reported in developing countries [30] [35] [36]. However, CKD is not identified as a main target in the WHO strategy for the control of NCDs [37] even though it is a major risk factor closely 
related to the incidence and the consequences of high blood pressure, diabetes and cardiovascular diseases [37]. CKD predisposes persons to high blood pressure and cardiovascular disease (CVD) while diabetes, high blood pressure and CVD are major causes or comorbidities of CKD [37]. The measurement of glomerular filtration performed in this study enabled assessment of the burden of chronic kidney disease in the army. Two-thirds of participants were classified as having good glomerular filtration. However, one-third of participants were found to have stage $2 \mathrm{CKD}$, indicating a slight alteration of renal function that would require early management. However, this apparently favorable situation is deceiving because of the high prevalence of CKD risk factors such as high blood pressure, diabetes and overweight which, in most of cases, were discovered during this survey. To better care for patients with CKD, an approach based on prevention and early detection is needed.

\section{Limitations}

This study was conducted among military personnel, who are a special group because of rigorous medical screening given upon entry into the army. Thus, these results are likely to be an underestimation of data concerning general population. The cross-sectional nature of the study excluded those who were absent during the period of survey, but no absence was related to NCDs risk factors. Finally, the mobility of the military extended the duration of data collection.

\section{Conclusion}

The military does not appear to be spared from the problem of NCDs, despite rigorous entry medical screenings, periodic medical check-ups and its lifestyle based on training and regular, often intense, physical activity. This study has highlighted the importance of NCD risk factors in the Senegalese army and supports the development of a sector-specific program for primary prevention focused on health promotion. Such a program would have the advantage of being inexpensive and available everywhere, even during operations. Additionally, military families, civilian staff in the military and some civilian populations will benefit. These results allow for the interests of military health to guide social policy to combat NCDs, particularly as policies relate to investment in health promotion.

\section{Acknowledgements}

The authors would like to acknowledge the participants and the Army and Military Health Direction for their support of this study.

\section{Competing Interests}

The authors declare no competing interests.

\section{Authors' Contributions}

NDIAYE Abdoul Aziz: design, data collection, statistical analysis and manuscript re- 
view. Other authors: design and manuscript review. All the authors have read and approved the final version of the manuscript.

\section{References}

[1] Moodie, R., Stuckler, D., Monteiro, C., Sheron, N., Neal, B., Thamarangsi, T., et al. (2013) Profits and Pandemics: Prevention of Harmful Effects of Tobacco, Alcohol, and UltraProcessed Food and Drink Industries. The Lancet, 381, 670-679. https:/doi.org/10.1016/S0140-6736(12)62089-3

[2] Di Cesare, M., Khang, Y.-H., Asaria, P., Blakely, T., Cowan, M.J., Farzadfar, F., et al. (2013) Inequalities in Non-Communicable Diseases and Effective Responses. The Lancet, 381, 585-597. https:/doi.org/10.1016/S0140-6736(12)61851-0

[3] Bonita, R., Magnusson, R., Bovet, P., Zhao, D., Malta, D.C., Geneau, R., et al. (2013) Country Actions to Meet UN Commitments on Non-Communicable Diseases: A Stepwise Approach. The Lancet, 381, 575-584. https:/doi.org/10.1016/S0140-6736(12)61993-X

[4] Dalal, S., Beunza, J.J., Volmink, J., Adebamowo, C., Bajunirwe, F., Njelekela, M., et al. (2011) Non-Communicable Diseases in Sub-Saharan Africa: What We Know Now. International Journal of Epidemiology, 40, 885-8901. https:/doi.org/10.1093/ije/dyr050

[5] World Health Organization (2011) Global Status on Non-Communicable Diseases 2010. WHO, Geneva. http://www.who.int/nmh/publications/ncd_report_full_en.pdf

[6] Lozano, R., Naghavi, M., Foreman, K., Lim, S., Shibuya, K., Aboyans, V., et al. (2012) Global Mortality from 235 Causes of Death for 20 Age Groups in 1990 and 2010: A Systematic Analysis for the Global Burden of Disease Study 2010. The Lancet, 380, 2095-2128.

[7] Maire, B., Lioret, S., Gartner, A. and Delpeuch, F. (2002) Transition nutritionnelle et maladies chroniques liees a l'alimentation dans les pays en developpement. Cahiers santé, $12,45-55$.

[8] Frenk, J., Murray, C.J.L. and Bobadilla, J.L. (1989) Health Transition in Middle-Income Countries: New Challenges for Health Care. Health Policy Plan, 4, 29-39.

https:/doi.org/10.1093/heapol/4.1.29

[9] Omran, A.R. (1971) The Epidemiologic Transition: A Theory of the Epidemiology of Population Change. The Milbank Memorial Fund Quarterly, 29, 509-538. https:/doi.org/10.2307/3349375

[10] Murray, C.J., Ortblad, K.F., Guinovart, C., Lim, S.S., Wolock, T.M., Roberts, D.A., et al. (2014) Global, Regional, and National Incidence and Mortality for HIV, Tuberculosis, and Malaria during 1990-2013: A Systematic Analysis for the Global Burden of Disease Study 2013. The Lancet, 384, 1005-1070. https:/doi.org/10.1016/S0140-6736(14)60844-8

[11] OMS (2004) Rapport sur la Strategie mondiale pour l'alimentation, l'exercice physique et la santé. OMS, Geneve, 24p. http://www.who.int/dietphysicalactivity/strategy/eb11344/strategy_french_web.pdf

[12] OMS (2002) Rapport sur la sante dans le monde, 2002. Reduire les risques et promouvoir une vie saine. Serie de Rapports techniques N916, OMS, Geneve. http://www.who.int/nutrition/publications/obesity/WHO_TRS_916_fre.pdf

[13] Hogerzeil, H.V., Liberman, J., Wirtz, V.J., Kishore, S.P., Selvaraj, S., Kiddell-Monroe, R., et al. (2013) Promotion of Access to Essential Medicines for Non-Communicable Diseases: Practical Implications of the UN Political Declaration. The Lancet, 381, 680-689. https:/doi.org/10.1016/S0140-6736(12)62128-X

[14] Atun, R., Jaffar, S., Nishtar, S., Knaul, F.M., Barreto, M.L., Nyirenda, M., et al. (2013) Im- 
proving Responsiveness of Health Systems to Non-Communicable Diseases. The Lancet, 381, 690-697. https:/doi.org/10.1016/S0140-6736(13)60063-X

[15] Abegunde, D.O., Mathers, C.D., Adam, T. and Ortegon, M. (2007) The Burden and Costs of Chronic Diseases in Low-Income and Middle-Income Countries. The Lancet, 370, 19291938. https:/doi.org/10.1016/S0140-6736(07)61696-1

[16] Gaziano, T.A., Galea, G. and Reddy, K.S. (2007) Scaling up Interventions for Chronic Disease Prevention: The Evidence. Lancet, 370, 1939-1946. http://dx.doi.org/10.1016/S0140-6736(07)61697-3

[17] Seck, S.M., Gueye, S., Tamba, K. and Ba, I. (2013) Prevalence of Chronic Cardiovascular and Metabolic Diseases in Senegalese Workers: A Cross-Sectional Study 2010. Preventing Chronic Disease, 10, Article ID: 110339. http://dx.doi.org/10.5888/pcd10.110339

[18] World Health Organization. L'approche STEPwise de l'OMS pour la surveillance des facteurs de risque des maladies chroniques (STEPS). http://whqlibdoc.who.int/publications/2006/9789242593839_fre.pdf

[19] World HealthOrganization. Instrument STEPS de l'OMS pour la surveillance des facteurs de risque des maladies chroniques (STEPS) http://www.who.int/chp/steps

[20] Oladapo, O.O., Falase, A.O., Salako, L., Sodiq, O., Shoyinka, K. and Adedapo, K. (2010) A Prevalence of Cardiometabolic Risk Factors among a Yoruba South-Western Nigerian Population: A Population-Based Survey. Cardiovascular Journal of Africa, 21, 26-31.

[21] Msyamboza, K.P., Kathyola, D. and Dzowela, T. (2013) Anthropometric Measurements and Prevalence of Underweight, Overweight and Obesity in Adult Malawians: Nationwide Population Based NCD STEPS Survey. Pan African Medical Journal, 15, 108-118. http://dx.doi.org/10.11604/pamj.2013.15.108.2622

[22] American Diabetes Association (2004) Diagnosis and Classification of Diabetes Mellitus. Diabetes Care, 27, S5-S10. http://dx.doi.org/10.2337/diacare.27.2007.S5

[23] Expert Panel on Detection, Evaluation and Treatment of High Blood Cholesterol in Adults (2001) Executive Summary of the Third Report of the National Cholesterol Education Program (NCEP) Expert Panel on Detection, Evaluation and Treatment of High Blood Cholesterol in Adults (Adult Treatment Panel III). JAMA, 285, 2486-2497.

http://dx.doi.org/10.1001/jama.285.19.2486

[24] Agence Nationale d'Accreditation et d'Evaluation en Santé (2002) Diagnostic de l'insuffisance renale chronique chez l'adulte. Recommandations pour la pratique clinique. ANAES, Paris, $124 \mathrm{p}$.

http://www.hassantefr/portail/upload/docs/application/pdf/irc_chez_ladulte_2002_-_argu mentaire.pdf

[25] National Kidney Foundation (2002) K/DOQI Clinical Practice Guidelines for Chronic Kidney Disease: Evaluation, Classification and Stratification. American Journal of Kidney Diseases, 39, S1-S266.

[26] Levey, A.S., Bosch, J.P., Lewi, J.B., Greene, T., Rogers, N. and Roth, D. (1999) A More Accurate Method to Estimate Glomerular Infiltration Rate from Serum Creatinine: A New Prediction Equation. Annals of Internal Medicine, 130, 461-460. http://dx.doi.org/10.7326/0003-4819-130-6-199903160-00002

[27] Stevens, L.A., Coresh, J., Feldman, H.I., Greene, T., Lash, J.P., Nelson, R.G., et al. (2007) Evaluation of the Modification of Diet in Renal Disease Study Equation in a Large Diverse Population. Journal of the American Society of Nephrology, 18, 2749-2757. http://dx.doi.org/10.1681/ASN.2007020199 
[28] Mbaye, M.N., Niang, K., Sarr, A., Mbaye, A., Diedhiou, D., Ndao, M.D., et al. (2011) Aspects Epidemiologiques du diabete au Senegal : Resultats d'une enquete sur les facteurs de risque cardiovasculaire dans la ville de Saint-Louis. Médecine des Maladies Métaboliques, 6, 659-664. http://dx.doi.org/10.1016/S1957-2557(11)70343-1

[29] Sow, P.G., Ka, O., Goume, M., Tall, A.B. and Ndiaye, A.A. (2014) The Prevalence of Arterial Hypertension and Associated Factors in the Senegalese Population in Dakar. American Journal of Pharmacy and Health Research, 2, 97-105.

http://www.ajphr.com/archive/volume-2/april-2014-issue-4/204011.html

[30] Seck, S.M., Doupa, D., Gueye, L. and Dia, C.A. (2014) Epidemiology of Chronic Kidney Disease in Northern Region of Senegal: A Community-Based Study in 2012. Pan African Medical Journal, 18, 307-317. http://dx.doi.org/10.11604/pamj.2014.18.307.3636

[31] Conseil National de Lutte contre le Sida (2006) Rapport national de surveillance combine VIH/sida dans les Armées. Sénégal.

[32] Rapport étude FRAT (Sénégal) (2006) Etude d'identification des aliments vecteurs susceptibles d'être enrichis a grande échelle en micronutriments au Sénégal.

http://www.unicef.org/wcaro/english/wcaro_NMs_43_Senegal_foodfortification.pdf

[33] Lang, T. (1998) The New Globalisation, Food and Health: Is Public Receiving Its Due Emphasis? Journal of Epidemiology \& Community Health, 52, 538-539.

http://dx.doi.org/10.1136/jech.52.9.538

[34] Allani, R., Bouomrani, S., Mrabet, A., Belli, R., Saidi, O., Beji, M., et al. (2014) Prévalence du syndrome métabolique dans une cohorte de militaire du sud tunisien. International Review of the Armed Forces Medical Services, 87, 5-10.

[35] Jha, V., Gardia-Gardia, G., Iseki, K., Li, Z., Plattner, B., Saran, R., et al. (2013) Chronic Kidney Disease: Global Dimension and Perspectives. Lancet, 382, 260-272. http://dx.doi.org/10.1016/S0140-6736(13)60687-X

[36] Couser, W.C., Remuzzi, G. and Tonelli, M. (2011) The Contribution of Chronic Kidney Disease to the Global Burden of Major Noncommunicable Diseases. Kidney International, 80, 1258-1270. http://dx.doi.org/10.1038/ki.2011.368

[37] Lower, G.M. and Kanarek, M.S. (1982) The Mutation Theory of Chronic, Noninfectious Disease: Relevance to Epidemiologic Theory. American Journal of Epidemiology, 115, 803817.

\section{Abbreviations}

NCDs: non-communicable diseases;

MDRD: modification of diet in renal disease;

BMI: body mass index;

GFR: glomerular filtration rate;

CKD: chronic kidney disease. 
Submit or recommend next manuscript to SCIRP and we will provide best service for you:

Accepting pre-submission inquiries through Email, Facebook, LinkedIn, Twitter, etc. A wide selection of journals (inclusive of 9 subjects, more than 200 journals)

Providing 24-hour high-quality service

User-friendly online submission system

Fair and swift peer-review system

Efficient typesetting and proofreading procedure

Display of the result of downloads and visits, as well as the number of cited articles

Maximum dissemination of your research work

Submit your manuscript at: http://papersubmission.scirp.org/

Or contact health@scirp.org 